naturally, to the American scene. The mentality of McCarthyism is analysed in terms of various American historical movements, and it is shown how the isolationist type of outlook, when confronted with the challenge of communism, was led to support an extreme form of anti-intellectualism involving considerable loss of liberty and often unfair treatment for those individuals unlucky or unwise enough to get involved in alleged or real security cases. The mentality of the intellectual of the 30 's who became involved in communism out of naivety, largely because he distrusted his local politics and politicians, is also analysed.

All this may seem rather remote from the British point of view, and the book is certainly not to be recommended except to those of us who have definite interests in the American way of life. But some space is given to the British background and the very different attitude of mind about security to which it has led. While the Americans were worrying individuals like Owen Lattimore, who seems to have been nothing more than foolish at worst, our system was allowing such obvious culprits as Burgess and Maclean to make a clear get-away.

Prof. Shils is certainly no fellow-traveller, and his book is a plea for common sense. It is unfortunate that he does not do much to elaborate any measures which might help to safeguard liberties without jeopardizing reasonable security of national secrets. But one can hope that this and similar publications will help to educate the mind of the public about these matters.

H. W. B. SKINNER

\section{COMBUSTION IN HIGH-SPEED FLIGHT}

\section{Combustion Processes}

Edited by B. Lewis, R. N. Pease and H. S. Taylor. (High Speed Aerodynamics and Jet Propulsion, Vol. 2.) Pp. $x v+662$. (London: Oxford University Press, 1956.) 84s. net.

T TAD there been a Rip van Winkle among pre1 war combustion experts, it would be most interesting to-day to observe his reactions after a sleep of a mere twenty years duration. He would surely be even more confounded and confused than was his legendary original. Just as the ultra- and electron-microscopes have enabled man to probe more deeply into the fundamental mysteries of solid matter, so too in the field of combustion the application of many novel and varied techniques, accelerated by a major war, have combined to transform completely both the range and minutiæ of the subject.

"Combustion Processes" is the second of a series of works to be published by the Board of Editors of the Aeronautics Publications Programme at Princeton University. The project has the active support and encouragement of many industrial and research organizations. Under the chairmanship of Theodore von Kármán, and the present general editor, Joseph V. Charyk, the Board aims to treat comprehensively the basic principles and problems of aerodynamics and propulsion as applied to high-speed flight.

The present editors are fortunate in having the services of a galaxy of experts in the branches of technology discussed; there are indeed so many that it could not be other than invidious to single out individuals for mention in $a$ short review. It is perhaps due to the large number of individual authors involved that the system of classification of subjectmatter into parts, sections and chapters is not all that might be desired, but to emphasize unduly a minor criticism of this nature would be carping in the extreme. A more pertinent complaint might be that insufficient space is devoted to the practical applications of the theoretical and experimental studies detailed. Omissions on this score tend to render the work somewhat less attractive to students and to newcomers to the field, since, to them, the events or situations necessitating the exhaustive treatment of a given topic may not be immediately apparent. Nevertheless, as a detailed exposition of the present state of knowledge of combustion in the sphere for which it is intended the work will be of great value.

The first third of the subject-matter covers the basic tools of thermodynamics and chemical kinetics. Part 1, on thermodynamics, contains a useful section on computational methods; Part 2, on chemical kinetics, includes such topics as reactions at surfaces, fast reactions and non-equilibrium conditions, as well as detailed discussion of a selection of specific reactions, including the oxidation of paraffin hydrocarbons.

Further sections are devoted to the propagation of flame in gases, the combustion of liquids and solids and detonation processes. Gaseous combustion is exhaustively treated: appropriate sections deal with combustion wave theory in both turbulent and nonturbulent explosive mixtures as well as diffusion flames. The latter includes a discussion of unmixedness which gives rise to a lag between the entrainment of the combustion air and its reaction with the fuel.

Liquid and solid fuels are more than adequately treated. The section on liquid fuels follows the now almost classic procedure of breakdown into the individual processes of atomization, mixing, evapora. tion and combustion, and that on solid fuels emphasizes the obvious points of similarity and difference between the combustion of solid particles and liquid droplets. The latter section of necessity illustrates many of its arguments by reference to the combustion of carbon, but much recent information bearing on the possible use of metals as fuel is also given. Aware of the paucity of available data in this latter, comparatively unexplored field of research, the authors have shown some ingenuity in pointing to the application of work in such related fields as corrosion and low-temperature oxidation. They have rightly stressed the importance of factors governing ignition. Later chapters, dealing with liquid and solid propellants, repeat the useful technique of an earlier section: generalized treatments are followed by a discussion of the performance of selected propellant systems.

The reader of the last two sections, covering detonation and energy production by nuclear reactions, might be forgiven if he feels that, excellent as are the treatments of these topics, the latter, and, to a less extent, the former, are somewhat out of place in a treatise on combustion. However, this is a question which should, perhaps, be judged in relation to the series as a whole. To date, four of the projected twelve volumes of the series have been published. If the existing standards are maintained, workers in fields allied to modern flight propulsion, as well as many others, will eagerly await the appearance of the remainder. C. HuLSE 